Corrigendum

\title{
Corrigendum to "Oxidative Stress Alters the Profile of Transcription Factors Related to Early Development on In Vitro Produced Embryos"
}

\author{
Roberta Ferreira Leite, ${ }^{1}$ Kelly Annes, ${ }^{1}$ Jessica Ispada, ${ }^{2}$ Camila Bruna de Lima, \\ Érika Cristina dos Santos, ${ }^{1}$ Patricia Kubo Fontes, ${ }^{3}$ Marcelo Fábio Gouveia Nogueira, ${ }^{4}$ \\ and Marcella Pecora Milazzotto $\mathbb{D D}^{1}$ \\ ${ }^{1}$ Center of Natural and Human Sciences, Universidade Federal do ABC, Santo André, SP, Brazil \\ ${ }^{2}$ Institute of Biomedical Sciences, Universidade de São Paulo, São Paulo, SP, Brazil \\ ${ }^{3}$ Institute of Biosciences, Campus Botucatu, Department of Pharmacology, Universidade Estadual Paulista (UNESP), Botucatu, \\ SP, Brazil \\ ${ }^{4}$ School of Sciences and Languages, Campus Assis, Department of Biological Sciences, Universidade Estadual Paulista (UNESP), Assis, \\ SP, Brazil
}

Correspondence should be addressed to Marcella Pecora Milazzotto; marcella.milazzotto@ufabc.edu.br

Received 23 January 2018; Accepted 31 January 2018; Published 20 March 2018

Copyright (๑) 2018 Roberta Ferreira Leite et al. This is an open access article distributed under the Creative Commons Attribution License, which permits unrestricted use, distribution, and reproduction in any medium, provided the original work is properly cited.

In the article titled "Oxidative Stress Alters the Profile of Transcription Factors Related to Early Development on In Vitro Produced Embryos" [1], there was a missing grant and the Acknowledgments section should be corrected as follows:

The authors are grateful to the institution UFABC and to the Brazilian Science Foundations' CNPq, CAPES, and FAPESP for their financial assistance and to Seleon Biotecnologia Animal Ltda. and Conselho Nacional da Pecuária de Corte (CNPC) for their support (Grant no. 2015/03381-0, São Paulo Research Foundation (FAPESP)).

\section{References}

[1] R. F. Leite, K. Annes, J. Ispada et al., “Oxidative stress alters the profile of transcription factors related to early development on in vitro produced embryos," Oxidative Medicine and Cellular Longevity, vol. 2017, Article ID 1502489, 14 pages, 2017. 


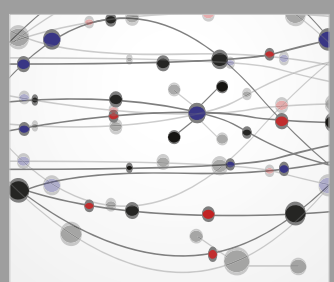

The Scientific World Journal
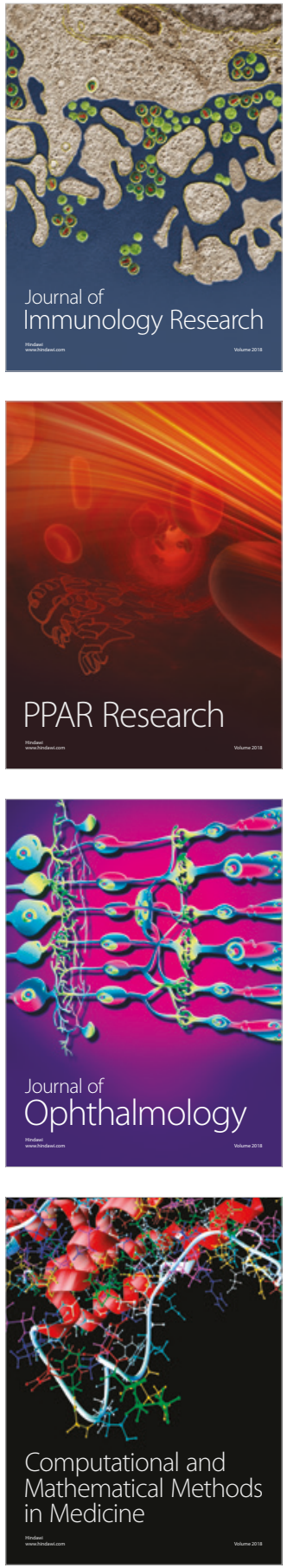

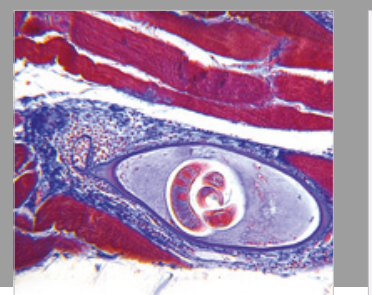

Gastroenterology Research and Practice

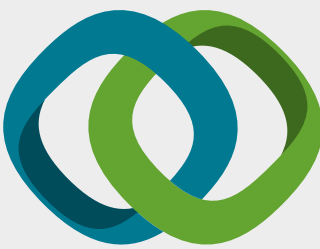

\section{Hindawi}

Submit your manuscripts at

www.hindawi.com
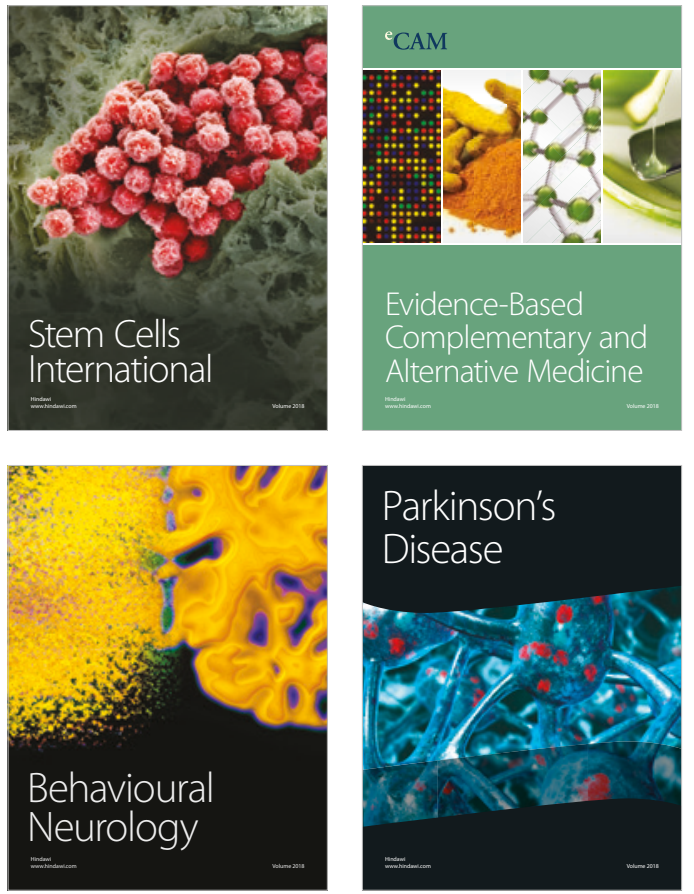

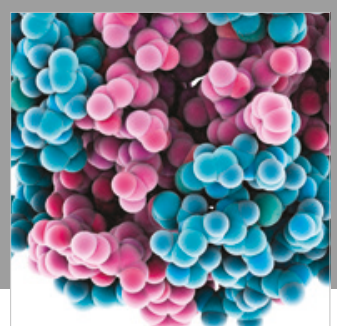

ournal of

Diabetes Research

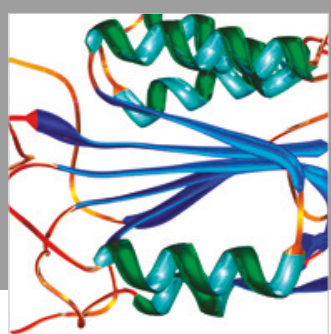

Disease Markers
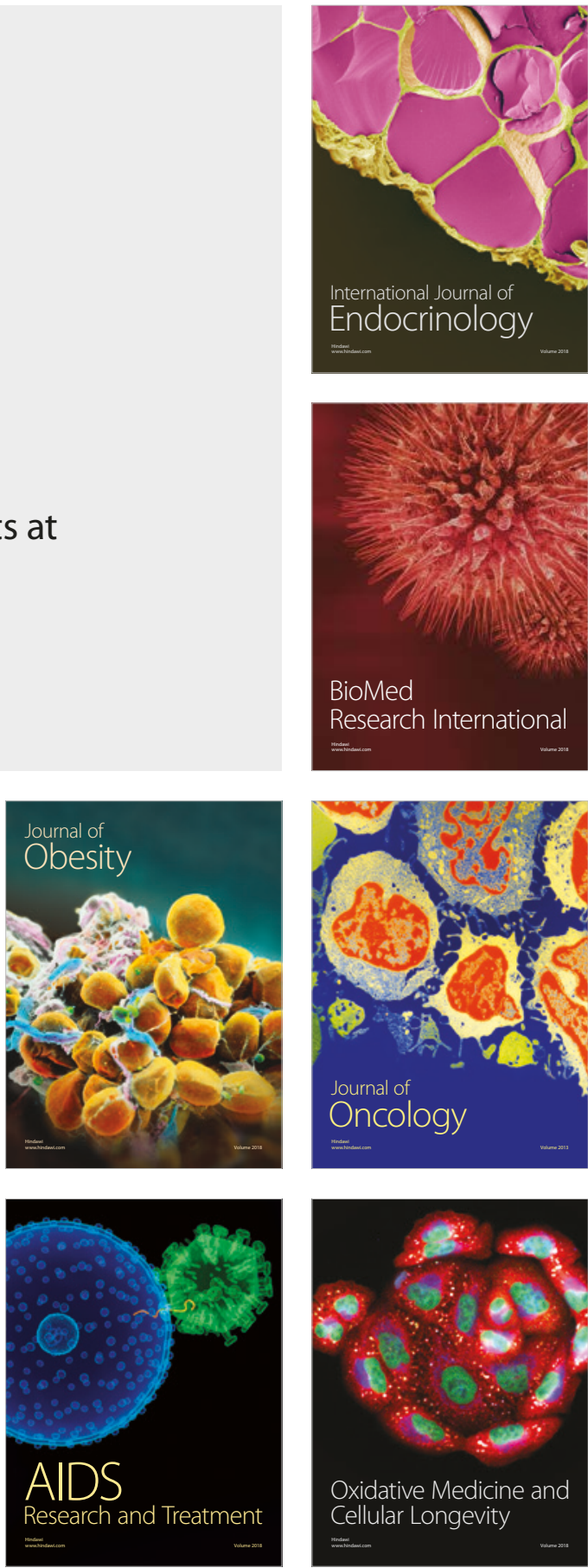